Vol. 2, No. 2, September 2020 e-ISSN: 2656-4882 p-ISSN: 2656-5935

\title{
Information System Strategic Planning using Ward and Peppard Methodology (Case Study: Nusatovel Salatiga)
}

\section{Perencanaan Strategis Sistem Informasi menggunakan Metodologi Ward dan Peppard (Studi Kasus: Nusatovel Salatiga)}

\author{
Angelina Agnes ${ }^{1}$, Agustinus Fritz Wijaya ${ }^{2}$ \\ Information System, Fakultas Teknologi Informasi, Satya Wacana Christian University, Indonesia \\ Email:1682017403@student.uksw.edu,2agustinus.wijaya@uksw.edu
}

\begin{abstract}
In the current era of globalization, IS and IT are utilized to be able to compete and increase company productivity. Information system strategic planning is one of the keys in achieving the target expected by the company. NUSATOVEL PT has implemented an information system, but there are still some parts that have not implemented the information system. The information system strategy planning model uses the Ward and Peppard method with SWOT analysis, Value Chain analysis, and Mc Farlan's Strategic Grid. By using this method various factors that affect the company, both internal and external are analyzed to get a formula that is the basis for preparing a new IS / IT strategy in the form of an IS / IT portfolio, which can then be used as a strategic plan. Research using this method makes strategic planning for IS / IT that can provide recommendations or solutions to the development and implementation of IS / IT that is more effective and efficient for the company. The proposed information system strategy, namely Graphic Design SI, Customer Relations Manager SI, SI Services, can be implemented within the next 3 (three) years.
\end{abstract}

Keywords: Information System Strategic Planning, Ward and Peppard, Strategy Proposition

\section{PENDAHULUAN}

Perencanaan strategis SI/TI memerlukan analisis lingkungan bisnis internal dan bisnis eksternal untuk menentukan strategi SI/TI pada Nusatovel dalam meningkatkan produktivitas perusahaan, dan mendukung perusahaan dalam meningkatkan efisiensi bisnis dan efektivitas manajemen dengan memberikan keunggulan bersaing. Dengan tetap bertahan dan terus melakukan 
pengembangan, perusahaan perlu mengimplementasikan sistem informasi yang sangat berpengaruh kritis terhadap keberhasilan bisnis perusahaan dimasa yang akan datang [1].

Nusatovel Salatiga merupakan travel agent yang melayani kebutuhan pelanggan akan jasa tour dan travel yang menarik dari mitra. SI/TI yang ada kurang maksimal contohnya Web yang digunakan kurang menarik dan sangat sederhana. Di bagian pemasaran, selain menggunakan web dan media social yaitu dengan grup whatsapp yang harus membuat grup terlebih dahulu dengan orang yang pernah melakukan transaksi di travel agent ini dan admin atau karyawan perusahaan membagikan poster diskon yang dapat digunakan. Serta belum ada nya aplikasi berbasis mobile di perusahaan. Hal ini mengakibatkan penggunaan aplikasi yang tidak optimal dan tidak selarasnya SI/TI dengan tujuan bisnis [2].

Untuk dapat mengatasi kendala-kendala yang ada, sangat diperlukan Perencanaan Strategis Sistem Informasi pada Nusatovel agar dapat memanfaatkan teknologi informasi secara menyeluruh serta mengikuti trend teknologi yang sedang berkembang seperti mobile. Maka dalam menyusun perencanaan strategis sistem informasi menggunakan metode Ward and Peppard karena metode ini dianggap paling efektif dan efisien untuk memenuhi kebutuhan informasi[3]. Beberapa metode analisis antara lain: analisis SWOT yaitu perencanaan strategis yang digunakan untuk mengevaluasi kekuatan (strengths), kelemahan (weaknesses), peluang (opportunities), dan ancaman (threats) dalam spekulasi bisnis, analisis Value Chain yaitu mengidentifikasikan aktivitas utama dan aktivitas pendukung perusahaan, dan McFarlan Strategic Grid yaitu untuk memetakan aplikasi sistem informasi [4].

\section{METODE}

Dalam penelitian ini menggunakan beberapa metode dalam penulisannya ataupun dalam pengumpulan data. Untuk metode penulisannya menggunakan metode penelitian deskriptif kualitatif dan studi dokumen. Deskriptif kualitatif merupakan pendekatan yang berusaha mendeskripsikan seluruh gejala atau keadaan yang ada, yaitu keadaan menurut apa adanya pada saat penelitian dilakukan. Metode penelitian ini juga mendeskripsikan dan menjabarkan mengenai langkah-langkah dalam menentukan sebuah perencanaan strategis sistem informasi, juga membahas beberapa metode atau tools yang digunakan dalam merumuskan sebuah perencanaan strategis yang nantinya akan menghasilkan rencana strategis yang lebih efektif dan efisien[5]. Studi dokumen sangat membantu dalam penelitian dan menjadi pelengkap bagi proses penelitian deskriptif kualitatif, karena banyak data yang tersimpan dalam bentuk dokumen. Bahkan kredibilitas hasil penelitian akan semakin tinggi jika menggunakan studi dokumen, namun dalam pemanfaatannya bahwa tidak semua dokumen memiliki kredibilitas yang tinggi, sehingga harus selektif. Dokumen merupakan catatan 
peristiwa yang sudah berlalu berbentuk tulisan, gambar, atau karya-karya monumental dari seseorang [6].

Selain metode penulisan dengan metode deskriptif kualitatif juga menggunakan metode pengumpulan data yang dilakukan kurang lebih dalam waktu 1 bulan, dalam pengumpulan data ini terdiri dari beberapa tahap, yaitu: tahap pertama melakukan observasi dan perijinan ke tempat studi kasus untuk melakukan wawancara. selanjutnya melakukan wawancara dengan 2 orang karyawan dan pengambilan data tentang profil perusahaan, penerapan penggunaan SI/TI yang ada dan bagian-bagian didalam perusahaan. Selanjutnya melakukan identifikasi masalah dan kebutuhan yang ada pada perusahaan. Dalam proses analisanya terdapat 4 tahapan, tahapan analisa lingkungan bisnis internal dan eksternal dengan analisis SWOT untuk mengidentifikasikan kekuatan, kelemahan, peluang, ancaman dan analisa Value Chain yang memetakan seluruh proses aktivitas utama dan aktivitas pendukung, analisa Lingkungan SI/TI internal dan eksternal yang dilihat dalam cakupan tren teknologi dan kondisi bisnis[7]. Setelah melakukan analisa terhadap tahapan tersebut maka tahapan selanjutnya adalah Pemetaan Aplikasi menggunakan Analisis McFarlan Strategic Grid dan pemetaan dilakukan empat kuadran yaitu strategic, hight potential, key operational, support). Tahapan keempat menyusun rencana strategi SI/TI, strategi bisnis, strategi manajemen. Setelah melakukan tahapan-tahapan tersebut selanjutnya melakukan tahapan kelima menyusun usulan aplikasi dan mengimplementasikan usulan aplikasi yang diterapkan [6].

\section{RESULTS AND DISCUSSION}

Dalam metode Ward and Peppard langkah-langkah untuk menentukan perencanaan strategis SI/TI dibutuhkan beberapa langkah utama yaitu:

\section{1) Analisis Lingkungan Bisnis Internal/Eksternal SWOT}

Analisis lingkungan bisnis internal untuk mengidentifikasikan apa yang perlu dikembangkan, dan dengan menganalisis lingkungan eksternal perencanaan strategi dapat melihat dan melaksanakan strategi yang paling tepat[8].

Langkah pertama dalam perencanaan strategis sistem informasi di Nusatovel yaitu analisis lingkungan bisnis internal dan bisnis eksternal sekaligus dengan menggunakan alat analisis SWOT (Strengths, Weakness, Opportunities, and Threats) [9]. Analisis SWOT digunakan untuk mengetahui kekuatan, kelemahan, peluang, dan ancaman Nusantara Tour baik yang berasal dari dalam maupun dari luar perusahaan. 
Vol. 2, No. 2, September 2020

p-ISSN: 2656-5935 http://journal-isi.org/index.php/isi

e-ISSN: 2656-4882

\section{SWOT ANALYSIS}

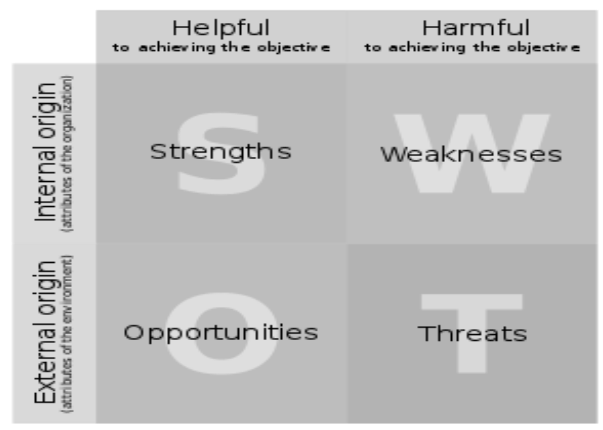

Gambar 1. Model SWOT Analisis

1) Kekuatan (Strengths): perusahaan memiliki modal finansial dan sumber daya manusia yang cukup untuk dapat menerapkan sistem informasi sesuai dengan kebutuhan perusahaan.

2) Kelemahan (Weakness): sumber daya manusia di perusahaan masih perlu dilatih dalam penggunaan sistem informasi dikarenakan latar belakang pendidikan bukan di bidang teknologi informasi.

3) Peluang (Opportunities): perkembangan teknologi informasi yang pesat dan ketersediaan aplikasi enterprises yang dapat langsung digunakan tanpa perlu mengembangkan sehingga perusahaan dapat dengan cepat beradaptasi dengan lingkungan teknologi informasi yang baru.

4) Ancaman (Threats): meningkatnya persaingan antar perusahaan yang menggunakan sistem informasi dan teknologi informasi sebagai alat bantu utama untuk proses operasional di perusahaan.

\section{2) Analisis Value Chain}

Perencanaan strategis sistem informasi manajemen di Nusatovel memiliki beberapa aktivitas utama dan aktivitas pendukung. Berikut pendefinisian proses bisnis di Nusatovel digambarkan menggunakan Porter's Value Chain Activity atau Activity Diagram yang terlihat pada gambar di bawah ini. 
Vol. 2, No. 2, September 2020

p-ISSN: 2656-5935 http://journal-isi.org/index.php/isi e-ISSN: 2656-4882

\begin{tabular}{|c|c|c|c|}
\hline 点点 & $\begin{array}{c}\text { PENJUALAN } \\
\text { DAN } \\
\text { PEMBOKINGAN } \\
\text { TIKET }\end{array}$ & $\begin{array}{c}\text { TRAVEL } \\
\text { CONSULTANT }\end{array}$ & PROMOSI \\
\hline \multirow{6}{*}{ 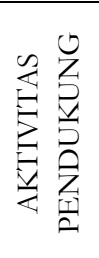 } & \multicolumn{3}{|l|}{ AKUNTASI } \\
\hline & \multicolumn{3}{|c|}{ MANAJEMEN SUMBER DAYA MANUSIA } \\
\hline & \multicolumn{3}{|c|}{ TURIS SERVIS, DESTINASI DAN FASILITAS } \\
\hline & \multicolumn{3}{|c|}{ PERSONALIA DAN ADMINISTRASI } \\
\hline & \multicolumn{3}{|l|}{ DESAIN WEB } \\
\hline & \multicolumn{3}{|l|}{ PEMBUKUAN } \\
\hline
\end{tabular}

Gambar 2. Diagram Value Chain Nusatovel

Aktivitas utamanya antara lain a). penjualan dan pembookingan tiket kepada customer yang dilayani kebutuhannya oleh bagian karyawan untuk melakukan reservasi tiket, perubahan atau pembatalan tiket, mengatur jadwal perjalanan. b). Travel Consultant bertanggung jawab dalam kebutuhan perjalanan (tiket, visa, paspor) merencanakan dan menjual transportasi dan akomodasi bagi pelanggan. Menentukan tujuan, jenis transportasi, tanggal, biaya, dan akomodasi yang diperlukan saat perjalanan. Dan menjelaskan, merencanakan, mengatur jadwal dan menjual paket wisata. c). promosi ini dikelola perencanaan pelaksanaannya oleh Brand Manager dan juga dibantu oleh karyawan untuk melakukan pemasaran tersebut.

Aktivitas pendukungnya antara lain a) akuntansi yang fungsinya untuk mencatat transaksi keuangan atau laporan keuangan, transaksi penjualan tiket dimana memudahkan untuk pengelolaan keuangan yang baik agar tidak mengalami kerugian dan pencatatan akuntansi juga didalam perusahaan yang bergerak di bidang travel agent akan melibatkan lebih banyak akun dan kompleks. akuntansi sama saja dengan pembukuan yang mencatat laporan laba rugi. b). manajemen sumber daya manusia pada tenaga kerja di setiap bidangnya agar memahami tugas dan tanggung jawabnya dan dilaksanakan dengan baik, contohnya karyawan yang bagian reservasi dan ticketing. c). turis servis, destinasi, fasilitas, dapat menjadi travel consultant yang dapat memberikan tempat destinasi dan fasilitas yang memadai agar para turis tertarik untuk menggunakan travel agent ini. d). personalia dan administrasi, pengelolaan modal dan akunting perusahaan salah satunya juga menganalisis dan menyusun anggaran pendapatan dan pengeluaran tahunan yang akan datang, mempertanggungjawabkan administrasi dan harta benda milik perusahaan, salah satunya juga menyelesaikan pembayaran gaji bagi karyawan. e). desain web membutuhkan pengembangan, oleh IT consultant ataupun desain grafisnya. 


\section{3) Analisis Lingkungan Internal / External SI/TI}

Dalam melakukan identifikasi penerapan sistem informasi di Nusatovel maka dilakukan analisis lingkungan sistem informasi secara internal yang digunakan di perusahaan saat ini yang dilakukan terhadap segala sumber daya sistem informasi dan teknologi informasi yang tersedia. Sumber daya yang dimaksud adalah sistem informasi dalam bentuk aplikasi, teknologi informasi dalam bentuk perangkat keras, dan sumber daya manusia yaitu pengguna sistem informasi atau manajemen sistem informasi yang terdapat di perusahaan saat ini. Adapun daftar sistem informasi yang digunakan oleh perusahaan saat ini yaitu seperti pada Tabel di bawah ini:

Tabel 1. Sistem Informasi pada Nusatovel

\begin{tabular}{llll}
\hline No & \multicolumn{1}{c}{$\begin{array}{c}\text { Nama Sistem } \\
\text { Informasi }\end{array}$} & Pengguna & \multicolumn{1}{c}{$\begin{array}{c}\text { Jenis } \\
\text { Aplikasi }\end{array}$} \\
\hline 1. & SI Promosi & Bagian Promosi & Web \\
\hline 2. & SI Penjualan & Bagian Penjualan & Web \\
\hline 3. & SI Desain Grafis & $\begin{array}{l}\text { Bagian Desain } \\
\text { Grafis }\end{array}$ & Dekstop \\
\hline
\end{tabular}

Sistem informasi Promosi digunakan oleh bagian promosi dan berbentuk web, sistem informasi penjualan masih menggunakan web dan tidak berbasis mobile, sistem informasi desain grafis berbentuk desktop digunakan bagian design grafis.

\section{4) Strategi TI}

Kondisi untuk hardware terutama pada disk komputer yang sudah hampir penuh, mengharuskan untuk upgrade kapasitas komputernya. Dan juga untuk menghindari ada permasalahan pada komputer ataupun sistem informasi, meminta bagian IT atau teknisi paling tidak satu orang untuk berada di Salatiga. Jadi seketika terjadi server nya down atau ada masalah terhadap sistem tidak perlu menunggu teknisi dari Semarang.

\section{5) Strategi Bisnis SI/TI}

Rekomendasi strategi bisnis SI/TI tujuannya untuk pengembangan aplikasi yang berguna dimasa yang akan datang, antara lain:

1. Mengupgrade SI Desain Grafis

2. Mengupgrade SI Penggajian

3. Mengupgrade SI Jasa

4. Membuat SI Customer Relationship Management 


\section{6) Strategi Manajemen SI/TI}

Berdasarkan hasil wawancara, pada Nusatovel Salatiga tidak ada ada teknisi khusus untuk menangani permasalahan terhadap hardware dan software. Perusahaan harus memiliki teknisi IT untuk mengontrol terhadap hardware dan software agar dapat memaksimalkan kinerja IT perusahaan.

\section{7) Usulan Aplikasi}

Berdasarkan hasil analisis yang diperoleh dari beberapa tahapan sebelumnya yaitu analisis lingkungan bisnis perusahaan baik lingkungan internal maupun eksternal, maka kemudian akan menjadi masukan pada tahapan usulan strategi solusi sistem informasi untuk Nusantara Tour[10]. Disini kita mengusulkan SI Desain Grafis untuk di update software nya karena sudah banyak yang menggunakan software yang terbaru dan demikian juga untuk SI Penggajian dan SI Jasa juga di upgrade software nya. Untuk SI Customer Relationship Management untuk bisa dibuatkan software nya karena di Nusatovel masih menggunakan promosi lewat social media seperti (WhatsApp, Instagram dll). Adapun usulan strategi solusi sistem informasi Nusantara Tour adalah seperti pada Tabel 2 berikut.

Table 2. Usulan Sistem Informasi Nusatovel

\begin{tabular}{llll}
\hline No & $\begin{array}{l}\text { Nama Sistem } \\
\text { Informasi }\end{array}$ & Pengguna & Jenis Aplikasi \\
\hline 1. & SI Desain Grafis & Bagian Desain Grafis & Desktop \\
2. & $\begin{array}{l}\text { SI Customer } \\
\text { Relationship }\end{array}$ & Bagian Marketing & Web \\
& Management & & \\
3. & SI Penggajian & Bagian Akuntansi & Desktop \\
4. & SI Jasa & Bagian karyawan & Web \\
& & & \\
\hline
\end{tabular}

Adapun matriks McFarlan Strategic Grid yang digunakan untuk pemetaan aplikasi mendatang di Nusatovel dapat dilihat pada tabel di bawah ini.

Tabel 3. Pemetaan Sistem Informasi Nusatovel Mc Farlan's Strategic

$\begin{array}{cc}\text { STRATEGIC } & \text { HIGH POTENTIAL } \\ \text { SI Customer Relationship } & \text { SI Jasa } \\ \text { Management } & \\ \text { SI Penggajian } & \text { SI Desain Grafis } \\ \text { SUPPORT } & \text { KEY } \\ \end{array}$


Pada tabel tersebut terdapat aplikasi-aplikasi yang ada pada kuadrannya masingmasing. Pada kuadran key operational adalah SI Desain Grafis, aplikasi yang pada saat ini dipakai oleh Nusatovel dan menunjang kelangsungan perusahaan serta membutuhkan pengembangan untuk meningkatkan manfaat produktivitas dalam perusahaan. Ini masih terus digunakan karena terkait dengan postingan di media sosial(Instagram), pemberian informasi melalui website, pembuatan brosur serta menyampaikan informasi yang jelas dan mudah dicerna.

Pada kuadran strategic adalah SI Customer Relationship Management, aplikasi yang memiliki pengaruh kritis terhadap keberhasilan bisnis perusahaan dimasa yang akan datang dan mendukung perusahaan dengan memberikan keunggulan bersaing. Jadi dari Nusatovel mengoptimalkan keberadaan customer dengan mengaktifkan aplikasi berbasis Customer Relationship Management, jika bisa memaksimalkan aplikasi ini dapat meningkatkan omzet pemasarannya. Dengan menerapkan aplikasi ini dapat membantu perusahaan dalam memaintenance terutama divisi Corporate Travel Management bisa bekerja lebih maksimal dan terarah sesuai target yang diharapkan perusahaan, serta perusahaan juga bisa mengelola semua data dan informasi dari customer, sehingga customer bisa ditingkatkan dari customer biasa menjadi loyal customer.

Pada kuadran high potential adalah SI Jasa, dimana aplikasi yang mungkin sangat penting dalam mencapai kesuksesan dimasa mendatang. Aplikasi ini untuk jasa pemesanan tiket, memudahkan untuk mencari dan menampilkan daftar jadwal dan harga tiket atau paket wisata, atau hotel.

Pada kuadran support adalah SI Penggajian, aplikasi yang berharga tetapi tidak kritikal untuk kesuksesan dan mendukung perusahaan dalam meningkatkan efisiensi bisnis dan efektivitas manajemen namun tidak memberikan keunggulan bersaing. Dengan aplikasi ini mempermudah segala aktivitas yang dilakukan perusahaan terutama HRD yang mengelola gaji karyawan dan sangat menguntungkan. Mengijinkan karyawan dan manajer untuk mengakses data gaji terbaru menggunakan handphone dan informasi login pribadi, serta mendapatkan akses ke informasi bisa meningkatkan kepuasan karyawan dan menghemat waktu HRD.

\section{8) Pemetaan Implementasi Usulan Sistem Informasi}

Analisis ini dilakukan untuk menentukan aplikasi apa saja yang akan di-upgrade, delete, dan direncanakan oleh perusahaan seperti pada tabel berikut. 
Vol. 2, No. 2, September 2020

p-ISSN: 2656-5935 http://journal-isi.org/index.php/isi e-ISSN: 2656-4882

Table 4. Perencanaan Usulan Aplikasi

\begin{tabular}{lccc}
\hline Usulan Aplikasi & Upgrade & Delete & Rencanakan \\
\hline SI Desain Grafis & $\checkmark$ & - & $\checkmark$ \\
SI Customer Relationship & - & - & $\checkmark$ \\
Management & & & \\
SI Penggajian & $\checkmark$ & - & - \\
SI Jasa & $\checkmark$ & - & - \\
& & & \\
\hline
\end{tabular}

SI Desain Grafis sudah ada maka demi menunjang kinerja bisnis perusahaan maka direncanakan Upgrade dan direncanakan untuk pembuatannya. SI Customer Relationship Management direncanakan. SI Penggajian dan SI Jasa direncanakan Upgrade nya.

Pada tabel 5 merupakan rencana implementasi usulan sistem informasi yang akan di buat selamat kurun waktu 3 tahun kedepan dengan mempertimbangkan banyak kemungkinan, terutama modal dan waktu yang dimiliki.

Tabel 5. Pemetaan Implementasi Usulan SI Nusatovel

\begin{tabular}{lllll}
\hline Solusi SI/TI & 2020 & 2021 & 2022 & 2023 \\
\hline SI Desain & Key & & & \\
Grafis & Operational & & & \\
SI Customer & & Strategic & & \\
Relationship & & & & \\
Management & & & High & \\
SI Jasa & & Potential & \\
SI Penggajian & & & & Support \\
\hline
\end{tabular}

\section{KESIMPULAN}

Berdasarkan hasil penelitian yang telah dilakukan, untuk saat ini Nusatovel sudah menerapkan sistem informasi namun belum optimal. Analisa yang dilakukan menggunakan metode Ward and Peppard dengan analisis SWOT, analisis Value Chain dan McFarlan Strategic Grid menghasilkan solusi yang dirancang berdasar analisis lingkungan bisnis internal/eksternal, analisis lingkungan SI/TI internal/eksternal. Perencanaan Strategis SI/TI menghasilkan 4 usulan sistem informasi untuk 3 tahun mendatang yaitu Sistem informasi Desain Grafis, Sistem informasi Customer Relationship Management, Sistem informasi Penggajian dan Sistem informasi Jasa. 
Dengan adanya perencanaan strategis sistem informasi diharapkan Nusatovel dapat terus meningkatkan produktivitas perusahaan, dan mendukung perusahaan dalam meningkatkan efisiensi bisnis dan efektivitas manajemen dengan memberikan keunggulan bersaing.

\section{REFERENSI}

[1] D. S. Wardhana and A. R. Tanaamah, "Perencanaan Strategis Sistem Informasi Menggunakan Metode Ward And Peppard Studi Kasus Cv XYZ," Aiti, vol. 16, no. 1, pp. 18-30, 2019, doi: 10.24246/aiti.v16i1.1830 .

[2] I. G. Susanto and A. F. Wijaya, "Renstra SI atau TI Unit Bisnis (Branch IT Services) Menggunakan Metode Ward and Peppard (Studi Kasus: PT. XYZ)," J. SITECH Sist. Inf. dan Teknol., vol. 2, no. 1, pp. 1-12, 2019, doi: 10.24176/ sitech.v2i1.3053.

[3] H. Clement and D. Salois-Swallow, Strategic planning for an information system., vol. 8 Pt 2. 1995.

[4] I. Supriyantoko, "Perancangan Strategis Sistem Informasi di Smk Diponegoro 1 Jakarta," Elinvo (Electronics, Informatics, Vocat. Educ., vol. 3, no. 2, pp. 10-18, 2019, doi: 10.21831/elinvo.v3i2.21862.

[5] F. Wibowo and A. F. Wijaya, "Perencanaan Strategis SI/TI Menggunakan Metode Ward and Peppard (Studi Kasus : Sinode GKJ)," Semin. Nas. Sist. Inf. Indones., no. November, pp. 39-44, 2018.

[6] Y. Firmansyah and D. Purwaningtias, "Analisa Metodologi Ward \& Peppard Dalam Penentuan Perencanaan Strategis SI/TI," Cybernetics, vol. 1, no. 02, p. 70, 2017, doi: 10.29406/cbn.v1i02.725.

[7] Ari Wedhasmara, "LANGKAH-LANGKAH PERENCANAAN STRATEGIS SISTEM INFORMASI DENGAN MENGGUNAKAN METODE WARD AND PEPPARD | Wedhasmara | Jurnal Sistem Informasi," Jsi, vol. VOL. 1, NO, no. 1, pp. 14-22, 2017, [Online]. Available: https://ejournal.unsri.ac.id/index.php/jsi/article/view/704.

[8] A. Sutanto, P. Sudarmaningtyas, and E. Sutomo, "Perencanaa Strategis Sistem dan Teknologi Informasi Pada PT QTA Travelindo Jaya Surabaya," vol. 5, no. 7, pp. 3-10, 2016.

[9] A. Setiawan and I. Beni, "Perencanaan Strategik Sistem Informasi pada Perusahaan Penerbitan dengan Metode Ward and Preppard : Studi Kasus pada Penerbit Rekayasa Sains Bandung," vol. 11, no. 3, pp. 308-325, 2012.

[10] F. N. Salisah and Syaifullah, "Analisis Perencanaan Strategi Sistem Informasi Pada Institusi Pendidikan," J. Sains, Teknol. Ind., vol. Vol.11 No., pp. 1-9, 2013. 